06;13.3

\title{
Характеристики поверхности циркониевого сплава Э-110, модифицированного способом воздушно-термического оксидирования
}

\author{
() В.И. Проскуряков, И.В. Родионов, В.А. Кошуро
}

Саратовский государственный технический университет им. Гагарина Ю.А., Саратов, Россия

E-mail: prosku.94@mail.ru

Поступило в Редакцию 25 октября 2019 г.

В окончательной редакции 27 ноября 2019 г.

Принято к публикации 17 февраля 2020 г.

Приведены результаты исследования влияния режимов воздушно-термического оксидирования на элементный и фазовый состав, морфологию и микротвердость модифицированной поверхности циркониевого сплава Э-110. Установлено, что при обработке образцов на поверхности формировались покрытия, элементный и фазовый состав которых в основном зависел от температурных режимов оксидирования. Существенное влияние на морфологию и толщину оказывали температура реакционной среды и продолжительность обработки. Установлено, что при температурах оксидирования 400 и $500^{\circ} \mathrm{C}$ с продолжительностью 1,2 и $3 \mathrm{~h}$ реализуются наиболее целесообразные режимы для формирования механически прочных покрытий.

Ключевые слова: циркониевый сплав, воздушно-термическое оксидирование, структура, микротвердость.

DOI: 10.21883/PJTF.2020.09.49372.18085

В процессе эксплуатации изделия из циркониевых сплавов, используемые в ядерной энергетике, медицинской технике, приборостроении, машиностроении и других отраслях современной промышленности, утрачивают свою работоспособность и функциональное назначение, что связано с разрушением поверхностного слоя. Для решения данной проблемы активно развивается направление, связанное с нанесением различных функциональных покрытий, а также разработкой перспективных ресурсосберегающих методов модификации поверхности циркониевых изделий [1-3].

В настоящее время для повышения эксплуатационных характеристик циркония в большинстве случаев используются методы, относящиеся к электрохимической обработке [4-7]. Однако многие из этих методов характеризуются сложностью управления технологическим процессом и токсичным действием применяемых рабочих электролитов.

Актуальным направлением развития современных процессов обработки поверхности является разработка ресурсосберегающих способов получения полифункциональных покрытий на металлах и сплавах различного назначения. Для улучшения эксплуатационных характеристик металлических изделий в различных отраслях техники широкое применение нашли способы газотермического оксидирования [8]. К таким способам можно отнести метод воздушно-термического оксидирования, характеризуемый относительной простотой реализации процесса, а также возможностью варьирования функциональных свойств покрытий в широких диапазонах $[9,10]$.

Известно, что твердость окисленного циркония может достигать $16.6 \mathrm{GPa}$ [11]. В результате оксидирования металла происходит изменение его физико-механических свойств, структуры, а также элементного и фазового состава. Знание характера происходящих изменений необходимо для оптимизации технологии производства изделий, поверхность которых подвергается модификации. Однако в настоящее время в работах, посвященных процессу воздушно-термического оксидирования циркония, вопрос структурно-фазовых превращений остается не до конца изученным. Поэтому исследование физикомеханических характеристик покрытий, сформированных технологически простым и ресурсосберегающим методом воздушно-термического оксидирования, остается актуальным.

Целью настоящей работы является исследование влияния режимов газотермической обработки, а именно воздушно-термического оксидирования, на фазовый и элементный состав, морфологию, толщину и микротвердость оксидированной поверхности циркониевого сплава Э-110.

В исследованиях использовались циркониевые образцы из сплава марки Э-110 размером $10 \times 10 \times 2 \mathrm{~mm}$. Образцы подвергались предварительной воздушноабразивной обработке порошком электрокорунда дисперсностью 200-250 $\mu \mathrm{m}$ при давлении воздуха 0.5-0.6 МРа. Очистка от загрязнений осуществлялась с использованием ультразвуковой ванны „Кристалл$2.5^{\text {“ }}$ в водном растворе этилового спирта в течение $20 \mathrm{~min}$. После очистки проводилась сушка в муфельной печи „СНОЛ-1.6“ при температуре $50 \pm 10^{\circ} \mathrm{C}$ в течение $30 \mathrm{~min}$. Оксидное покрытие формировалось методом воздушно-термического оксидирования в лабораторной трубчатой электропечи сопротивления при температурах в рабочей зоне $T=400,500,600$ и $700^{\circ} \mathrm{C}$ и продолжительности процесса $\tau=1,2$ и $3 \mathrm{~h}$. 
Таблица 1. Влияние параметров воздушно-термического оксидирования на элементный состав покрытий (at.\%)

\begin{tabular}{c|c|c|c|c|c|l}
\hline $\begin{array}{c}\text { Температура } \\
T,{ }^{\circ} \mathrm{C}\end{array}$ & $\begin{array}{c}\text { Продолжитель- } \\
\text { ность } \tau, \mathrm{h}\end{array}$ & $\begin{array}{c}\text { Область } \\
\text { на рис. } 2\end{array}$ & $\mathrm{O}$ & $\mathrm{Al}$ & $\mathrm{Ca}$ & $\mathrm{Zr}$ \\
\hline 400 & 1 & 1 & 76.2 & 1.13 & 0.82 & 21.85 \\
& & 2 & 75.81 & 1.08 & 0.71 & 22.4 \\
& & 3 & 71.75 & 1.12 & 0.60 & 26.53 \\
400 & 3 & 1 & 72.42 & 5.29 & 0.22 & 22.07 \\
& & 2 & 71.55 & 5.10 & 0.21 & 23.14 \\
700 & & 3 & 72.35 & 4.00 & 0.15 & 23.5 \\
& 1 & 1 & 71.25 & 4.91 & & 23.84 \\
700 & & 2 & 71.49 & 3.83 & & 24.68 \\
& 3 & 1 & 71.08 & 5.17 & & 23.75 \\
& & & & & &
\end{tabular}

Элементный состав и морфология покрытий исследовались методами энергодисперсионного рентгенофлуоресцентного анализа (погрешность концентраций \pm 0.5 at.\%) и растровой электронной микроскопии на электронном микроскопе „MIRA II LMU“ с детектором „INCA PentaFETx3“".

Фазовый состав устанавливался методом рентгенофазового анализа с помощью дифрактометра ДРОН-4, снабженного рентгеновской трубкой с медным анодом, в $\mathrm{Cu} K_{\alpha}$-излучении при сканировании брэгговского угла со скоростью $2 \mathrm{deg} / \mathrm{min}$. Идентификация фаз на получаемых дифрактограммах проводилась с помощью компьютерной программы, содержащей данные картотек ASTM и JCPOS.

Структура покрытия также исследовалась методом оптической микроскопии с использованием микроскопа „МБС-10М“ при 112-кратном увеличении. Величина открытой пористости, линейные размеры зерен и дефектов, а также толщина покрытия определялись с использованием компьютерной программы графической обработки микроизображений „Metallograph“. При этом анализировалось несколько участков покрытия площадью $5 \mathrm{~mm}^{2}$ для получения среднестатистических значений элементов морфологии [11]. Статистическая обработка результатов исследования проводилась с помощью программы „DataFit 9 .

Микротвердость измерялась с использованием прибора „ПМТ-3М“ при нагрузке на индентор $1.961 \mathrm{~N}$ (ISO 6507-1:2005).

Согласно данным проведенного анализа, в элементный состав покрытий, полученных в результате оксидирования, входили $\mathrm{Al}, \mathrm{O}, \mathrm{Ca}$ и $\mathrm{Zr}$ (табл. 1). Наличие следового количества примесей алюминия и кальция связано с предварительной воздушно-абразивной обработкой и последующей промывкой в воде. Установлено, что температура и продолжительность оксидирования существенно влияют на элементный состав. Наличие высокого содержания кислорода показывает, что при заданных в эксперименте температурных режимах окси- дирования поверхность сплава Э-110 активно поглощает кислород из воздуха реакционной среды с формированием оксидного слоя.

Данные рентгенофазового анализа показали, что после предварительной воздушно-абразивной обработки в приповерхностном слое образцов происходит частичный переход фазы $\alpha-Z r$ в фазу $\beta-Z r$. Также установлено, что на поверхности после воздушно-термической модификации формируются структуры, состоящие преимущественно из диоксида $\mathrm{ZrO}_{2}$ с моноклинной решеткой. При анализе объемных долей содержания в покрытии указанных фаз выявлено, что основную долю составляют диоксид $\mathrm{ZrO}_{2}$ и $\alpha-\mathrm{Zr}$ с наибольшей интенсивностью дифракционных пиков на рентгеновской дифрактограмме (рис. 1).

Морфология покрытия, сформированного способом воздушно-термического оксидирования, является структурно-гетерогенной (рис. 2, $a, b)$. Существенные изменения морфологии происходят при увеличении температуры оксидирования. При температуре $700^{\circ} \mathrm{C}$ на поверхности образцов появляются трещины, рост которых зафиксирован с увеличением продолжительности оксидирования. Также визуализируется отслоение верхнего слоя оксидного покрытия (рис. 3). Изменения структуры поверхности зависят также от продолжительности термического воздействия. Так, при повышении продолжительности обработки оксидные кристаллы существенно укрупняются, что придает рельефу поверхности сглаженный характер. Согласно результатам гранулометрического анализа, при увеличении температуры с 400 до $700^{\circ} \mathrm{C}$ среднее количество зерен уменьшается более чем в 3 раза (табл. 2). При этом размеры пор и зерен изменяются от 7-10 до 9-12 $\mu \mathrm{m}$ соответственно.

Важными характеристиками покрытия являются пористость и толщина. Максимальная величина суммарной открытой пористости составляет 48\% при продолжительности оксидирования $2 \mathrm{~h}$ и температуре $400^{\circ} \mathrm{C}$, а минимальное значение $(10 \%)$ пористость принимает при

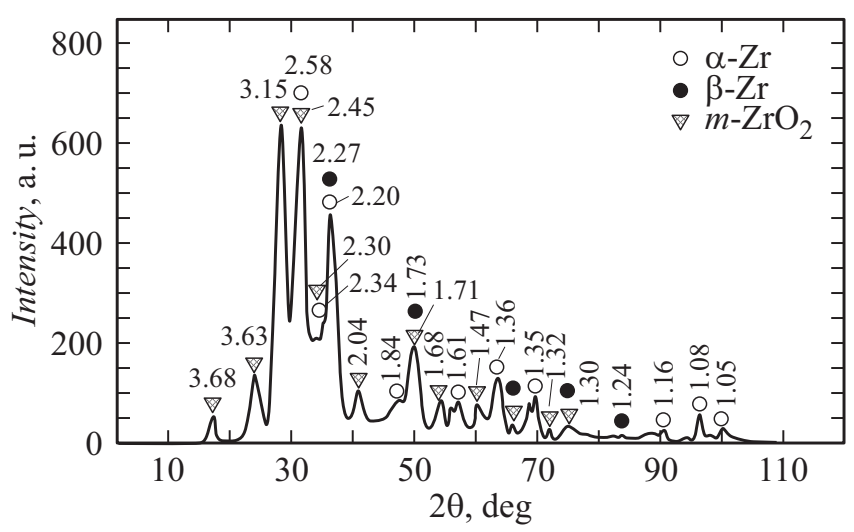

Рис. 1. Дифрактограмма поверхностного слоя циркониевого сплава Э-110, модифицированного воздушно-термическим оксидированием при $T=400^{\circ} \mathrm{C}$ и $\tau=1 \mathrm{~h}$. Числа около пиков межплоскостные расстояния $d$ (в $\AA$ ). 

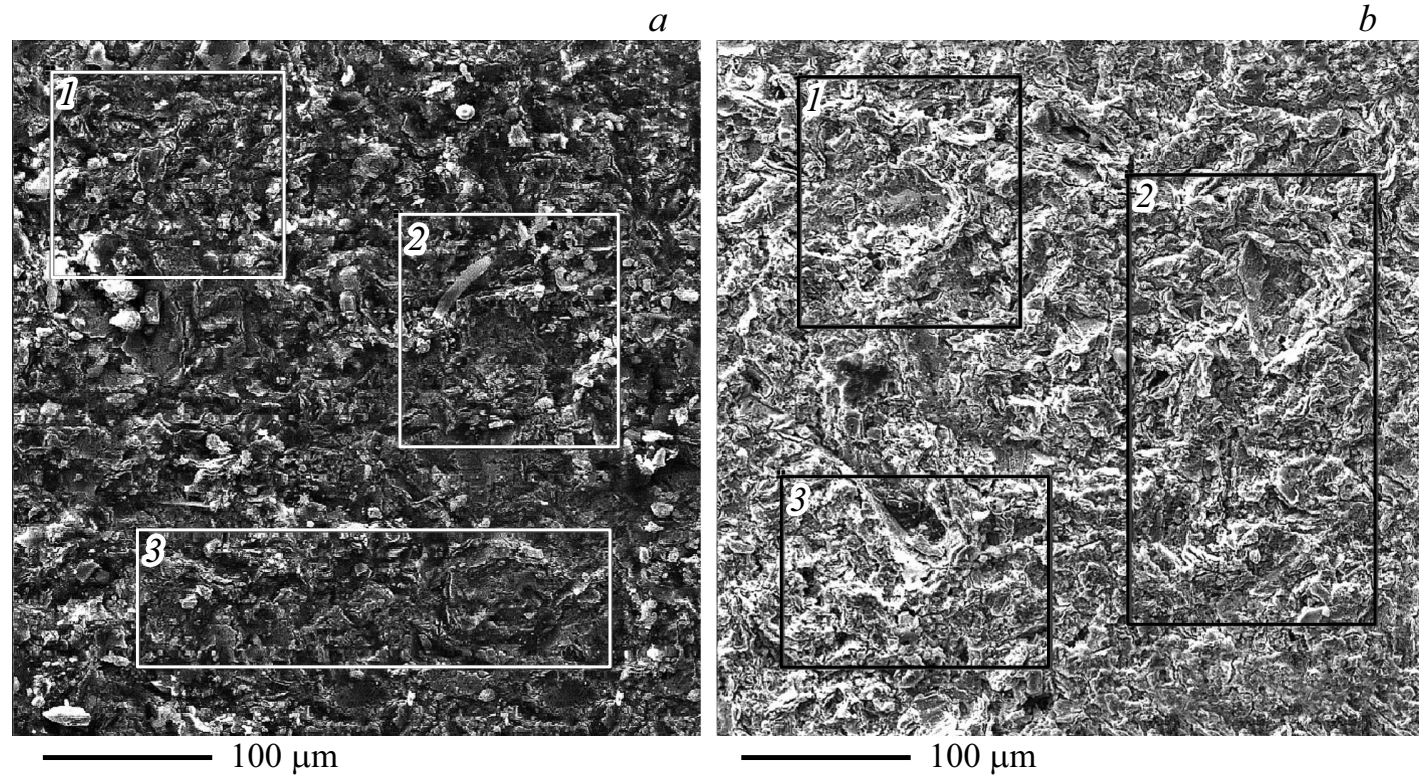

Рис. 2. Морфология поверхности оксидного покрытия, полученного в результате оксидирования при температуре $400^{\circ} \mathrm{C}$ и продолжительности $1(a)$ и $3 \mathrm{~h}(b) .1-3-$ обозначения областей, по которым проводился энергодисперсионный рентгенофлуоресцентный анализ.

Таблица 2. Результаты программной обработки морфологических характеристик оксидных покрытий на поверхности образцов при различных режимах (площадь исследуемой поверхности $S=5 \mathrm{~mm}^{2}$ )

\begin{tabular}{|c|c|c|c|c|c|c|c|c|}
\hline \multirow{2}{*}{\multicolumn{2}{|c|}{ Режим обработки }} & \multicolumn{7}{|c|}{ Характеристики поверхности } \\
\hline & & \multicolumn{3}{|c|}{ Частицы } & \multicolumn{4}{|c|}{ Поры } \\
\hline$T,{ }^{\circ} \mathrm{C}$ & $\tau, \mathrm{h}$ & $\begin{array}{l}\text { Коли- } \\
\text { чество }\end{array}$ & $\begin{array}{c}\text { Средний } \\
\text { размер, } \\
\mu \mathrm{m}\end{array}$ & $\begin{array}{c}\text { Средняя } \\
\text { площадь, } \\
\mu \mathrm{m}^{2}\end{array}$ & $\begin{array}{l}\text { Коли- } \\
\text { чество }\end{array}$ & $\begin{array}{c}\text { Средний } \\
\text { размер, } \\
\mu \mathrm{m}\end{array}$ & $\begin{array}{c}\text { Средняя } \\
\text { площадь, } \\
\mu \mathrm{m}^{2}\end{array}$ & $\begin{array}{c}\text { Суммарная } \\
\text { пористость } \\
P, \%\end{array}$ \\
\hline 400 & $\begin{array}{l}1 \\
2 \\
3\end{array}$ & $\begin{array}{r}1831 \\
632 \\
1104\end{array}$ & $\begin{array}{l}6.87 \\
9.87 \\
9.34\end{array}$ & $\begin{array}{r}7.48 \\
21.73 \\
12.53\end{array}$ & $\begin{array}{r}172 \\
1988 \\
370\end{array}$ & $\begin{array}{l}8.77 \\
8.13 \\
6.24\end{array}$ & $\begin{array}{l}35.65 \\
15.58 \\
24.52\end{array}$ & $\begin{array}{l}31 \\
48 \\
42\end{array}$ \\
\hline 500 & $\begin{array}{l}1 \\
2 \\
3\end{array}$ & $\begin{array}{r}865 \\
1187 \\
1004\end{array}$ & $\begin{array}{r}11.00 \\
9.05 \\
9.01\end{array}$ & $\begin{array}{r}13.50 \\
9.87 \\
11.93\end{array}$ & $\begin{array}{l}190 \\
166 \\
268\end{array}$ & $\begin{array}{l}6.77 \\
7.17 \\
7.94\end{array}$ & $\begin{array}{l}33.05 \\
35.91 \\
28.94\end{array}$ & $\begin{array}{l}38 \\
35 \\
40\end{array}$ \\
\hline 600 & $\begin{array}{l}1 \\
2 \\
3\end{array}$ & $\begin{array}{r}1162 \\
614 \\
189\end{array}$ & $\begin{array}{l}9.20 \\
5.67 \\
3.30\end{array}$ & $\begin{array}{r}11.06 \\
8.87 \\
1.78\end{array}$ & $\begin{array}{r}1426 \\
542 \\
144\end{array}$ & $\begin{array}{r}7.92 \\
5.75 \\
11.15\end{array}$ & $\begin{array}{r}17.40 \\
7.84 \\
39.32\end{array}$ & $\begin{array}{l}36 \\
22 \\
10\end{array}$ \\
\hline 700 & $\begin{array}{l}1 \\
2 \\
3\end{array}$ & $\begin{array}{l}258 \\
366 \\
273\end{array}$ & $\begin{array}{l}12.96 \\
10.29 \\
12.95\end{array}$ & $\begin{array}{l}30.22 \\
20.31 \\
23.03\end{array}$ & $\begin{array}{r}140 \\
210 \\
39\end{array}$ & $\begin{array}{r}10.01 \\
9.82 \\
19.13\end{array}$ & $\begin{array}{l}33.31 \\
19.17 \\
72.71\end{array}$ & $\begin{array}{l}17 \\
18 \\
22\end{array}$ \\
\hline
\end{tabular}

продолжительности нагрева $3 \mathrm{~h}$ и температуре $600^{\circ} \mathrm{C}$. Толщина сформированных покрытий в большей степени зависит от температуры оксидирования. Наибольшей толщиной $560 \mu \mathrm{m}$ обладали покрытия, сформированные при температуре $700^{\circ} \mathrm{C}$ и продолжительности оксидирования $3 \mathrm{~h}$, а минимальное значение толщины $(11 \mu \mathrm{m})$ имели покрытия при температуре $600^{\circ} \mathrm{C}$ и продолжительности $1 \mathrm{~h}$. При формировании покрытия большой толщины поверхность приобретает высокоразвитую тре- щиноватую структуру. При этом наблюдается отсоединение крупных частиц покрытия от материала основы из-за возникновения в оксидных слоях больших внутренних напряжений.

Микротвердость сформированного оксидного слоя достигала максимального значения $19.5 \pm 0.1 \mathrm{GPa}$ при температуре $600^{\circ} \mathrm{C}$ и продолжительности $2 \mathrm{~h}$. Дальнейшее увеличение времени оксидирования и температуры обработки приводило к снижению микротвердости. Ми- 


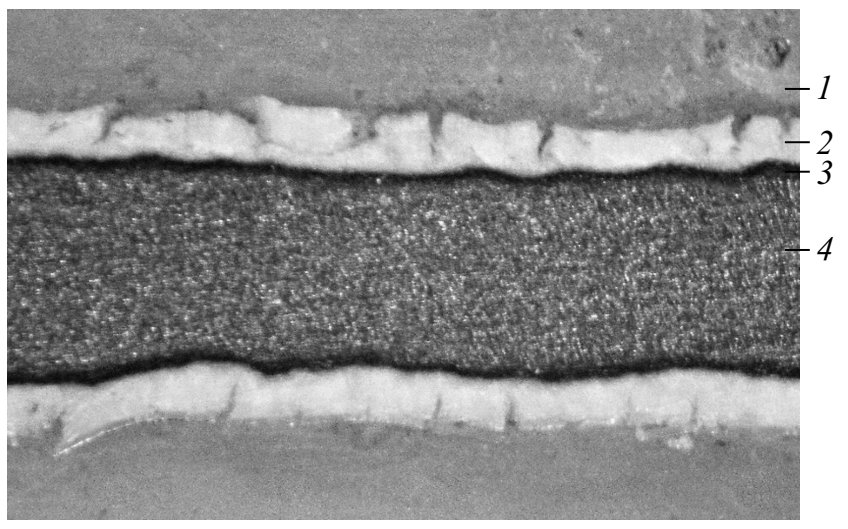

Рис. 3. Микрошлиф образца циркония после воздушнотермического оксидирования. 1 - эпоксидная смола, 2 - сформированное оксидное покрытие, 3 - зона упрочнения (поверхностный слой металла), 4 - основа металла.

нимальное значение микротвердости $6.1 \pm 0.1 \mathrm{GPa}$ было получено при температуре $400^{\circ} \mathrm{C}$ и продолжительности оксидирования $1 \mathrm{~h}$ при микротвердости исходного циркониевого образца $2.6 \pm 0.1 \mathrm{GPa}$.

Полученные результаты показывают, что при температурах оксидирования 400 и $500^{\circ} \mathrm{C}$ с продолжительностью 1, 2 и 3 h реализуются наиболее целесообразные режимы для формирования функциональных механически прочных покрытий. При указанных режимах величина открытой пористости равна $30-40 \%$, толщина покрытий не превышает $60 \mu \mathrm{m}$, микротвердость поверхности изменяется в диапазоне от $6.1 \pm 0.1$ до $19.4 \pm 0.1 \mathrm{GPa}$. Из анализа приведенных данных следует, что выбранные в эксперименте режимы воздушно-термического оксидирования циркониевых образцов позволяют получить покрытия с такой совокупностью характеристик микротвердости, морфологических параметров, элементного и фазового состава, которая позволяет рекомендовать сформированные оксидные структуры для использования в качестве упрочняющих поверхностных слоев различных циркониевых изделий.

\section{Финансирование работы}

Исследования выполнены при финансовой поддержке Минобрнауки РФ в рамках государственного задания образовательным организациям высшего образования, подведомственным Минобрнауки РФ (проект № 11.1943.2017/4.6).

\section{Конфликт интересов}

Авторы заявляют, что у них нет конфликта интересов.

\section{Список литературы}

[1] Пилипенко Н.Н., Дробышевскал А.А., Ажсажа Р.В., Стадник Ю.С., Танщюра И.Г., Ковтеба Д.В. // J. Kharkiv National University. 2013. № 3. С. 105-109.

[2] Полетика Т.М., Нариманова Г.Н., Колосов С.В., Зуев Л.Б. // Прикладная механика и техническая физика. 2003. T. 44. № 2. C. 132-142.

[3] Zhu Y., Fu J., Zheng C., Ji Z. // Opt. Laser Technol. 2016. V. 83. P. 21-27.

[4] Кошуро В.А., Нечаев Г.Г., Лясникова А.В. // ЖТФ. 2014. T. 84. B. 10. C. $153-155$.

[5] Востриков А.А., Федяева О.Н., Шишкин А.В., Сокол М.Я. // Письма в ЖТФ. 2010. Т. 36. В. 17. Р. 1-8.

[6] Некрасова Н.Е., Кругликов С.С. // Физикохимия поверхности и защита материалов. 2011. Т. 47. № 6. С. 668-672.

[7] Борисов А.М., Востриков В.Г., Романовский Е.А., Ткаченко Н.В., Виноградов А.В., Крит Б.Л., Савушкина С.В., Полянский М.Н. // Поверхность. Рентгеновские, синхротронные и нейтронные исследования. 2013. № 4. С. 76-80.

[8] Fomina M., Koshuro V., Papshev V., Rodionov I., Fomin A. // Data Brief. 2018. V. 20. P. 1409-1414.

[9] Фомин А.А., Штейнгауэр А.Б., Родионов И.В., Фомина М.А., Захаревич А.М. // Письма в ЖТФ. 2013. Т. 39. B. 21. C. 70-75.

[10] Koshuro V., Fomina M., Voyko A., Rodionov I., Zakharevich A., Skaptsov A., Fomin A. // Compos. Struct. 2018. V. 202. P. 210-215.

[11] Baron C., Springer H. // Data Brief. 2017. V. 12. P. 692-708. 